\title{
Risk Identification of Heavy Rain-induced Muck soil Landslide
}

\author{
Shaojie Feng ${ }^{1}$ *, Hang $\mathrm{Hu}^{1}$, Aimin $\mathrm{Yao}^{2}$, Shiguo Sun ${ }^{1}$ \\ 1 School of Civil Engineering, North China University of Technology, Beijing 100144, P.R. China \\ 2 Beijing Urban Construction Exploration \& Surveying Design Research Institute Co., Ltd., Beijing \\ 100101, P.R. China \\ * Corresponding author: Shaojie Feng
}

\begin{abstract}
Based on Monte Carlo method, this paper calculates landslide probability of muck soil slopes under different rainfall time, rainfall intensity, soil permeability coefficient and slope angle, thus obtaining the probability samples of muck soil landslides. On this basis, logistic regression method of nonlinear classification is used for data fitting and analysis, thus establishing nonlinear function $Z=f(t, q, k, \tan \alpha)$. Function expression is derived by data fitting, and a landslide probability evaluation model is constructed. Based on analysis of engineering examples, the error between this method and the numerical calculation results is within 10\%, and the evaluation results are reasonable. It provides theoretical support for rapid identification of muck soil landslide risk under heavy rain conditions.
\end{abstract}

Keywords: Muck soil, heavy rain, landslide, risk identification

\section{Introduction}

Risk identification constitutes a key link in the intelligent landslide prevention and control system. The difficulty is to determine the probability of slope instability or the frequency of landslides [1,2]. Due to the influence of uncertain factors such as the environment, structure and characteristics of rock and soil on the side slope, reliability analysis based on probability statistics can reflect the safety of landslides more objectively and quantitatively than assessment based on safety factors, thus providing a basis for landslide disaster risk assessment [3] At present, scholars at home and abroad have conducted a lot of researches on landslide probability warning methods. Li Yuan [4] first introduced logistic regression model to regional rainfall-type landslide warning and forecast, and based on this, established the expression of the critical value of rainfall-induced regional landslides and the effect probability of rainfall against landslide. Qiao Jianping [5] analyzed the time probability, space probability and early warning probability of landslide warning by examining the correlation between landslide and rainfall, as well as the start value of rainfall-induced landslide, and calculated the occurrence frequency of rainfall-induced landslide in the danger zone, thus obtaining the warning probability of rainfall-induced landslide. Saha Sunil [6] used conditional probability statistics and machine learning algorithms to test the susceptibility of landslides in North Indochina, and used 12 landslide condition factors to verify the established model through Friedman's test method. Hidayat Rokhmat [7] developed a landslide warning system based on flood warning system platform for Indonesia. The system uses daily rainfall data, rainfall threshold methods and regional slope stability model based on instantaneous rainfall infiltration and grids to predict the occurrence of landslides. Lee Jung Hyun [8] used the Gumbel model to estimate the probability in exceeding the rainfall threshold, and combined the time probability of landslide occurrence with landslide sensitivity result of multi-layer perceptron model to estimate the risk of landslides at different time periods in the future.

In recent years, the method of using logistic regression model to calculate landslide probability has been widely used. Wang Zhaohua [9] used slope gradient, aspect and vegetation index as the influencing factors of landslide occurrence, calculated the probability of landslide occurrence through logistic regression model, thus obtaining the risk zoning of loess landslide in Lanzhou under different rainfall. Using knowledge simplification and prediction

ISSN: 0010-8189

www.converter-magazine.info 
result feedback method, Wei Xingjun [10] selected rainfall characteristics that affect the landslide disaster to establish a reduced logistic regression prediction model, which can effectively process massive high-dimensional rainfall data.

Muck soil features low strength and strong water permeability. Under heavy rainfall conditions such as rainstorm, rainwater will quickly penetrate into the muck soil, soften the soil, increase the soil's own weight and reduce the shear strength of the soil, thereby lowering side slope stability. Therefore, studying the method for identifying the risk of heavy rain-induced muck soil landslide carries important theoretical and application value.

\section{Logistic Regression Method of Nonlinear Classification}

Logistic Regression (LR in short) is a generalized linear regression analysis model. Different from the general linear regression model, logistic regression model limits the output value to the interval $[0,1]$ through the Sigmoid function $[11,12]$.

LR model is usually used to deal with regression problem where the dependent variable is a categorical variable. The weight function in the model is $\mathrm{B}_{0}+\mathrm{B}_{1} \mathrm{X}_{1}+\ldots+\mathrm{B}_{2} \mathrm{X}_{2} . \mathrm{B}_{\mathrm{i}}$ is an undetermined parameter, $\mathrm{X}_{\mathrm{i}}$ is an influencing factor, and the landslide probability corresponds to the weight function in the form of an implicit function. The implicit function is $\mathrm{P}(x)=\mathrm{L}\left(\mathrm{B}_{0}+\mathrm{B}_{1} \mathrm{X}_{1}+\ldots+\mathrm{B}_{2} \mathrm{X}_{2}\right)$. The value of the dependent variable $\mathrm{Z}$ is determined by $\mathrm{P}(\mathrm{x})$. The expression of the LR model is as follows.

The weight function is:

$$
\mathrm{Z}=\mathrm{B}_{0}+\mathrm{B}_{1} \mathrm{X}_{1}+\cdots+\mathrm{B}_{2} \mathrm{X}_{2}
$$

The probability implicit function is:

$$
\ln \left(\frac{\mathrm{P}(\mathrm{x})}{1-\mathrm{P}(\mathrm{x})}\right)=\mathrm{B}_{0}+\mathrm{B}_{1} \mathrm{X}_{1}+\cdots+\mathrm{B}_{2} \mathrm{X}_{2}
$$

From equations (1) and (2), the probability function can be derived as:

$$
\mathrm{P}(\mathrm{x})=\frac{\operatorname{Exp}\left(\mathrm{B}_{0}+\mathrm{B}_{1} \mathrm{X}_{1}+\cdots+\mathrm{B}_{2} \mathrm{X}_{2}\right)}{1+\operatorname{Exp}\left(\mathrm{B}_{0}+\mathrm{B}_{1} \mathrm{X}_{1}+\cdots+\mathrm{B}_{2} \mathrm{X}_{2}\right)}
$$

In formulas (1) (3), $\mathrm{Z}$ represents the sum of weights, which is also the slope state value. $\mathrm{P}(\mathrm{x})$ represents the probability of landslide, and the relationship curve between $\mathrm{Z}$ and $\mathrm{P}(\mathrm{x})$ constitutes the sigmoid function. The function image is shown in Figure 1. The above is the standard LR model. The landslide hazard factors considered in this paper include rainfall time $\mathrm{t}$, rainfall intensity $\mathrm{q}$, permeability coefficient $\mathrm{k}$ and slope angle tangent $\mathrm{i}(\tan \alpha)$. Weight function is used to calculate $\mathrm{Z}$ value, that is, linear classification, and there is a big error in the obtained result, leading to low reliability of the prediction model, so it is unsuitable for landslide prediction and early warning. Therefore, this paper takes a nonlinear classification model for calculation.

Common nonlinear classification models include kernel methods and decision trees [13,14]. This paper adopts a processing method similar to the kernel method [15], replacing the linear weight function in the standard logistic regression analysis with non-linear function $\mathrm{Z}=\mathrm{f}(\mathrm{t}, \mathrm{q}, \mathrm{k}, \tan \alpha)$, and obtaining the function expression via data fitting.

ISSN: 0010-8189

(C) CONVERTER 2020 


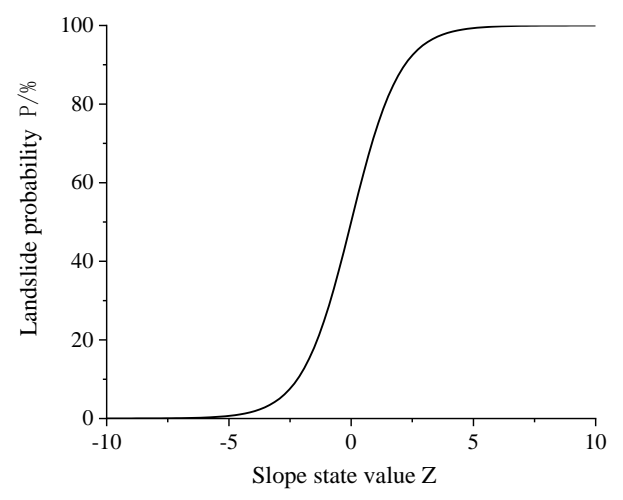

Fig 1: sigmoid function image

\section{Risk Assessment of Landslide of Muck soil Slope}

This paper uses the Monte Carlo method in the Geo-studio software to calculate the safety factor distribution of the muck soil slope. Since the software calculation does not give consideration to the influence of factors like rainfall erosion, soil softening, etc. bishop method with the lowest coefficient value is selected as the slope stability analysis method, with material parameters shown in Table 1. The slope model, the meshing of the slope model under slope angle of $30^{\circ}$ and the distribution of pore water pressure under initial conditions are shown in Figure 2.

Table 1 Material parameters

\begin{tabular}{|c|c|c|}
\hline Material parameters & Average value & Coefficient of variation \\
\hline Severity $\gamma / \mathrm{kN} \cdot \mathrm{m}^{3}$ & 17 & 0.12 \\
\hline Cohesion $\mathrm{c} / \mathrm{kPa}$ & 0.7 & 0.29 \\
\hline Internal friction angle $\varphi /{ }^{\circ}$ & 14 & 0.29 \\
\hline
\end{tabular}

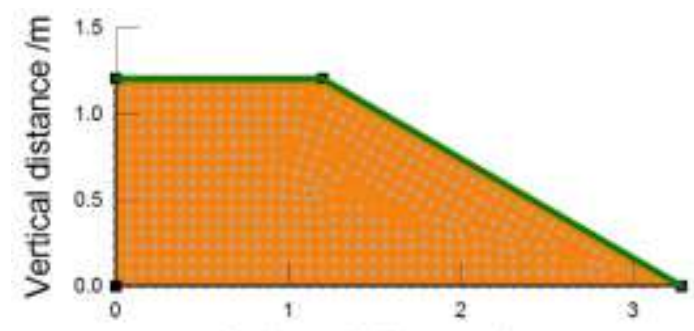

Horizontal distance $/ m$

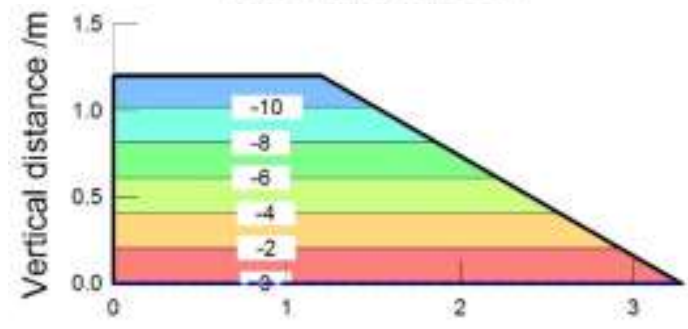

Horizontal distance /m

Fig 2: Grid division of side slope model and initial pore pressure

Geo-studio software is able to automatically search for the most dangerous slip surface and calculate the safety

ISSN: 0010-8189

(C) CONVERTER 2020 
coefficient of the critical slip surface in each set of tests. Each model is set with 2000 sets of tests. According to the calculated safety coefficient distribution, the software automatically distinguishes the landslide from the non-landslide test site, calculates the landslide probability, then uses sigmoid function to convert the calculated landslide probability into the slope state value $\mathrm{Z}$, and then derives the nonlinear function $z=\mathrm{f}(\mathrm{t}, \mathrm{q}, \mathrm{k}, \tan \alpha)$ through fitting.

There are many factors that affect the slope state value, including topography and landform, geological conditions, environmental conditions, and human activities [16,17]. This paper considers the four influencing factors of rainfall time $t$, rainfall intensity $q$, permeability coefficient $\mathrm{k}$ and slope angle tangent $\mathrm{i}$. Figure 3 is a curve reflecting the change of landslide probability and state value of a slope over time under a slope angle of $30^{\circ}$. In the early stage of rainfall, the landslide probability remains at 0 . At this time, the slope state value does not exist (it is an infinitesimal amount). From around the 15th day, the landslide probability begins to rise, and the state value also changes accordingly. By the 22nd day, the landslide probability has reached $100 \%$, with the state value becoming infinite. When only landslide probability interval $(0,1)$ is considered (without considering the probability of 0 and probability 1 ), there is obvious linear relationship between rainfall time and state coefficient. After the fitting curve is converted into curve about rainfall time vs. landslide probability through the sigmod function, it fits well with the original curve. Therefore, this paper fits the data points in the slope state value interval $[5,-5]$, and the corresponding landslide probability interval is $[0.007,0.993]$. The corresponding rainfall time interval in the following text is $\left[t_{0}, t_{n}\right]$.

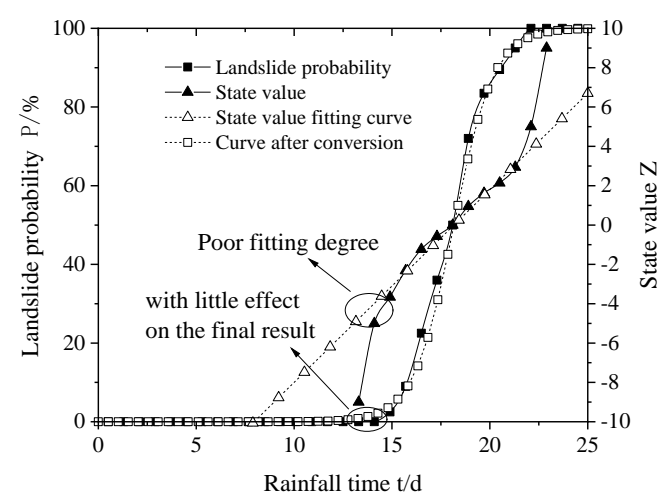

Fig 3: Relationship between rainfall time, landslide probability and state value

Based on the rainfall time-state value fitting curve, changes of rainfall intensity will affect the coefficient of the fitting curve. Then, rainfall intensity and the coefficient are fitted. Similarly, the permeability coefficient and slope angle are fitted and analyzed. This paper considers a total of 7 slope angle models of $30^{\circ}, 35^{\circ}, 40^{\circ}, 45^{\circ}, 50^{\circ}, 55^{\circ}$ and $60^{\circ}$, each model considers 9 rainfall times, 11 rain intensity values, and 8 permeability coefficients, totaling 5544 landslide probability data points. The specific content is shown in Table 2.

Table 2 Impact factors

\begin{tabular}{|c|c|c|}
\hline Material parameter & Number of points & Interval \\
\hline Rainfall time $\mathrm{t} / \mathrm{d}$ & 9 & {$\left[t_{0}, t_{n}\right]$} \\
\hline Rainfall intensity $\mathrm{q} / \mathrm{mm} \cdot \mathrm{d}^{-1}$ & 11 & {$[0.1 k, 1.1 k]$} \\
\hline Permeability coefficient $\mathrm{k} / \mathrm{mm} \cdot \mathrm{d}^{-1}$ & 8 & {$[20,160]$} \\
\hline
\end{tabular}

ISSN: 0010-8189 


\section{Establishment of Probability Formula for Heavy Rain-Induced Muck Soil Landslide}

\subsection{Consider the impact of rainfall time Potential cological risk}

The first fitting takes rainfall time $\mathrm{t}$ as the independent variable and slope state value $\mathrm{Z}$ as the dependent variable. Taking the model with slope angle $30^{\circ}$, permeability coefficient $100 \mathrm{~mm} / \mathrm{d}$, and rainfall intensity $100 \mathrm{~mm} / \mathrm{d}$ as an example, Figure 4 shows the t- $Z$ curve fitting effect diagram. The fitting formula selected in the figure is as follows:

$$
\mathrm{Z}=\mathrm{at}+\mathrm{b}
$$

By model fitting, a coefficient of 23.52 and b of 17.75 are obtained. The coefficient a represents the rate of increase in the landslide probability, which can be understood as the amount of rainwater infiltration per unit time, and the coefficient a has relation to the rainfall intensity $\mathrm{q}$, the permeability coefficient $\mathrm{k}$, and the slope ratio $\mathrm{i}$. The coefficient $b$ is the state coefficient of the slope at the initial moment. The goodness of fit considering the impact of rainfall time is shown in Table 3.

Table 3 The goodness of fit of the landslide probability formula considering rainfall time $t$

\begin{tabular}{|c|c|c|c|}
\hline Independent variable & Dependent variable & Fitting formula & $\begin{array}{l}\text { Coefficient of determination } R^{2} \\
\text { (average value) }\end{array}$ \\
\hline Rainfall time t/d & $\mathrm{Z}$ & $\mathrm{Z}=\mathrm{at}+\mathrm{b}$ & 0.94 \\
\hline
\end{tabular}

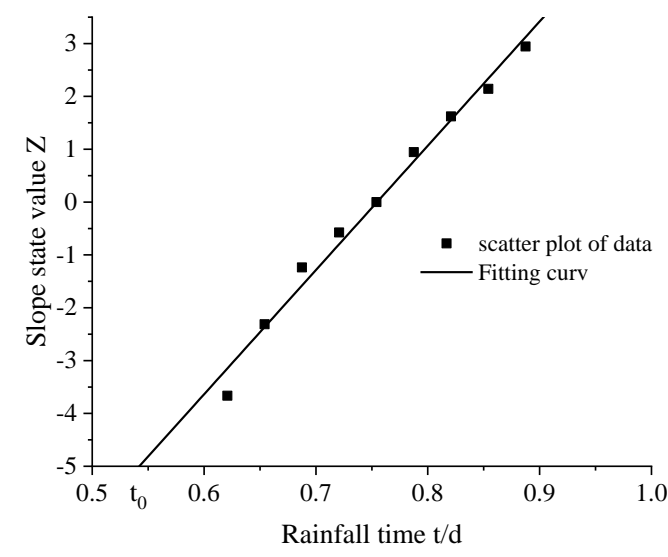

Fig 4: $t$-Z fitting curve diagram

\subsection{Consider the impact of rainfall intensity}

The second fitting takes rainfall intensity $\mathrm{q}$ as the independent variable, and the coefficients a and $\mathrm{b}$ derived from the first fitting as the dependent variables. Taking the model with a slope angle of 30 degrees and a permeability coefficient of $100 \mathrm{~mm} / \mathrm{d}$ as an example, the fitting effect is shown in Figure 5 . The growth curve function in the figure is used for fitting, with expression as follows:

$$
\mathrm{a}=\frac{1}{\mathrm{a}_{1}+\mathrm{a}_{2} \mathrm{a}_{3} \mathrm{q}}
$$

In the formula, $a_{1}, a_{2}, a_{3}$ are coefficients. The coefficient a mentioned above can be understood as the amount of

ISSN: 0010-8189 
rainwater infiltration per unit time. As the rainfall intensity increases, the amount of rainwater infiltration per unit time increases. When the rainfall intensity exceeds the permeability coefficient, the amount of rainwater infiltration per unit time tends to be stable, so the q-a fitting curve is s-shaped.

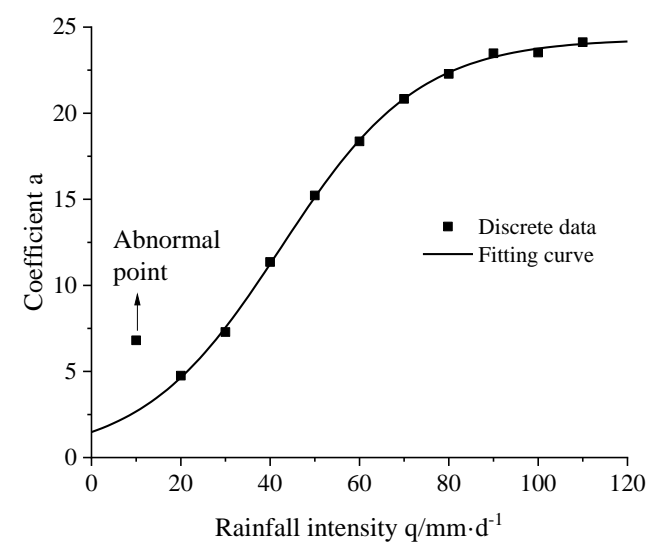

Fig 5: q-a fitting curve diagram

As mentioned earlier, the data points in the slope state value interval $[5,-5]$ have a high degree of fitting, while the coefficient $b$ is the slope state coefficient at the initial time. Therefore, when fitting the coefficient $b$, the scattered points are regular and inconspicuous. Here, we introduce a new variable $t_{0}$, where $t_{0}$ is the rainfall time required for the slope state value $\mathrm{Z}$ to reach -5 (that is, when the landslide probability is $0.67 \%$ ). It can be expressed in the following formula:

$$
a t_{0}+b=-5
$$

According to formula (4) and formula (6), the relationship between the slope state value $\mathrm{Z}$ and $t_{0}$ can be expressed as follows:

$$
\mathrm{Z}=\mathrm{a}\left(\mathrm{t}-\mathrm{t}_{0}\right)-5
$$

Taking a model with a slope angle of 30 degrees and a permeability coefficient of $100 \mathrm{~mm} / \mathrm{d}$ as an example, Figure 6 shows the curve fitting effect diagram. Through the scatter plot, it can be seen that $\mathrm{q}-t_{0}$ presents a power function distribution. The fitting formula is as follows:

$$
\mathrm{t}_{0}=\mathrm{b}_{1} \mathrm{q}^{-\mathrm{b}_{2}+\mathrm{b}_{3}}
$$

The coefficient $b_{1}$ derived from the model fitting is $499.4, b_{2}$ is 1.721 , and $b_{3}$ is 0.31 . As the rainfall intensity increases, the time required for the slope state value $\mathrm{Z}$ to reach -5 is shorter. The goodness of fit between rainfall intensity and coefficients $\mathrm{a}$ and $\mathrm{b}$ is shown in Table 4.

ISSN: 0010-8189 


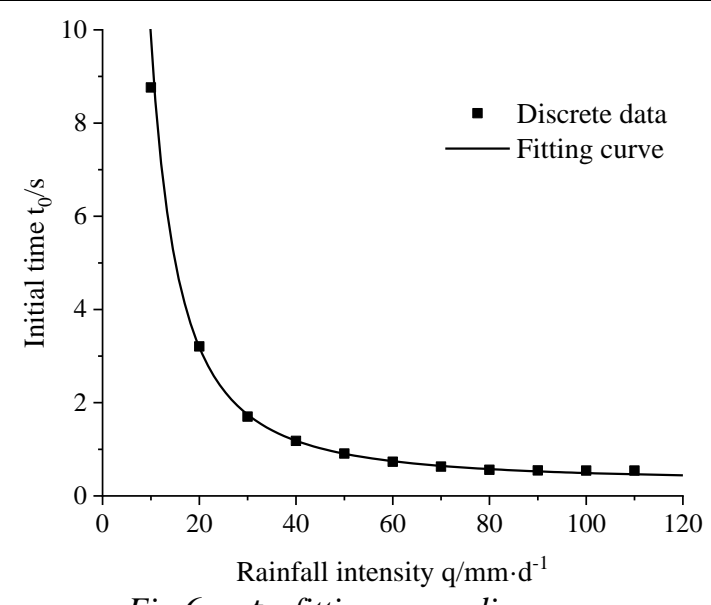

Fig 6: $q-t_{0}$ fitting curve diagram

From formulas (5), (7) and (8), the functional relationship between slope stability coefficient $\mathrm{Z}$ and rainfall time t, rainfall intensity q can be obtained. The expression is as follows:

$$
Z=\frac{t-b_{1} q^{-b_{2}-b_{3}}}{a_{1}+a_{2} a_{3}{ }^{a}}-5
$$

When the rainfall intensity approaches 0 , a is a constant and $t_{0}$ tends to be infinitely great. By substituting a and $t_{0}$ into formula (7), $\mathrm{z}$ tends to be infinitely small, and the landslide probability approaches 0 ; when the rainfall intensity tends to be infinitely great, $\mathrm{a}$ is a constant, $t_{0}$ is a constant. By substituting formula (7), it can be known that $\mathrm{z}$ only has relation to rainfall time. That is, when the amount of rainwater infiltration per unit time is a fixed value, landslide probability is only affected by rainfall time.

Table 4 Goodness of fit of landslide probability formula based on rain intensity $\mathrm{q}$

\begin{tabular}{|c|c|c|c|}
\hline Independent variable & Dependent variable & Fitting formula & $\begin{array}{c}\text { Coefficient of determination } \\
R^{2} \text { (average value) }\end{array}$ \\
\hline \multirow{2}{*}{$\begin{array}{c}\text { Rainfall intensity } \\
\mathrm{q} / \mathrm{mm} \cdot \mathrm{d}^{-1}\end{array}$} & $\mathrm{a}$ & $\mathrm{a}=\frac{1}{\mathrm{a}_{1}+\mathrm{a}_{2} \mathrm{a}_{3} \mathrm{q}}$ & 0.96 \\
\cline { 2 - 4 } & $\mathrm{t}_{0}$ & $\mathrm{t}_{0}=\mathrm{b}_{1} \mathrm{q}^{-\mathrm{b}_{2}+\mathrm{b}_{3}}$ & 0.97 \\
\hline
\end{tabular}

4.3 Consider the impact of permeability coefficient

The third fitting takes the permeability coefficient $\mathrm{k}$ as the independent variable, and the coefficients $\mathrm{a}_{1}, \mathrm{a}_{2}, \mathrm{a}_{3}, \mathrm{~b}_{1}, \mathrm{~b}_{2}, \mathrm{~b}_{3}$ obtained from the second fitting as dependent variables. Taking the slope angle of $30^{\circ}$ as an example, Figure $7 \sim$ Figure 9 are the fitting effect diagrams of permeability coefficient and correlation coefficient of the q-a curve. It can be seen from the scatter plot that $\mathrm{k}-a_{1}, \mathrm{k}-a_{2}$ and $\mathrm{k}-a_{3}$ are distributed in the form of a power function, and the selected fitting formula is as follows:

$\mathrm{k}-a_{1}$ fitting formula expression:

$$
a_{1}=\frac{A_{1}}{k}
$$

$\mathrm{k}-a_{2}$ fitting formula expression:

$$
a_{2}=\frac{A_{2}}{k}
$$

ISSN: 0010-8189 
$\mathrm{k}-a_{3}$ fitting formula expression:

$$
a_{3}=1-A_{3} k^{-0.9}
$$

The coefficient $A_{1}$ obtained by fitting the $30^{\circ}$ slope angle model is $4.1, A_{2}$ is 63.5 , and $A_{3}$ is 4.1 . The goodness of fit of the model under each working condition is shown in Table 5.

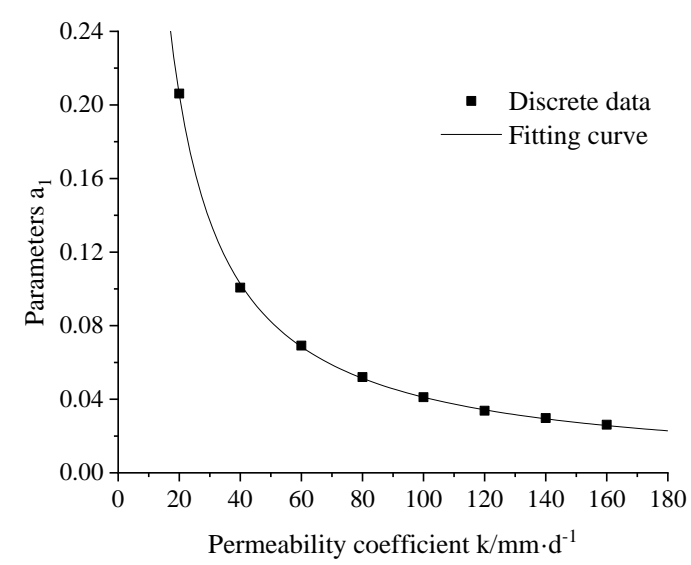

Fig 7: $k$ - $a_{1}$ fitting curve diagram

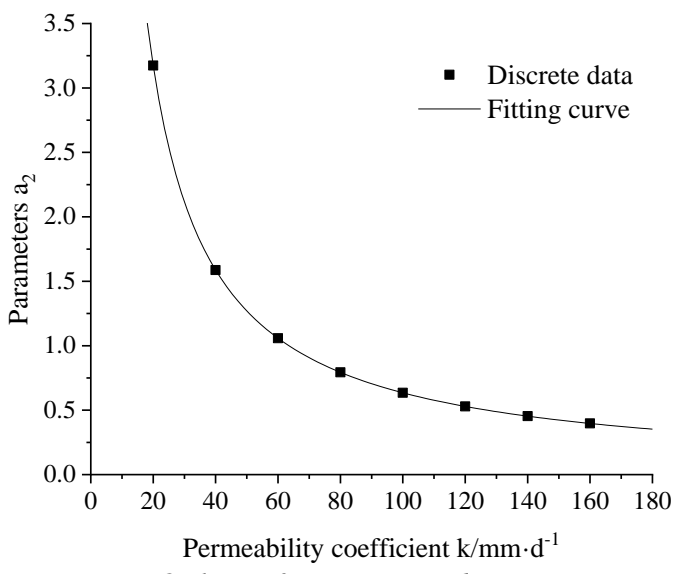

Fig 8: $k$ - $a_{2}$ fitting curve diagram

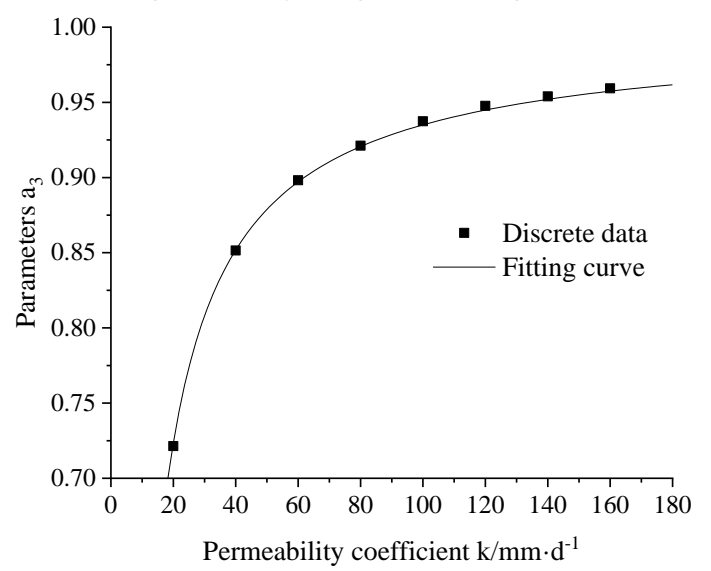

Fig 9: $k$ - $a_{3}$ fitting curve diagram

According to formulas (5), (10), (11) and (12), the functional relationship between coefficient a and permeability

ISSN: 0010-8189 
coefficient $\mathrm{k}$ can be obtained, with expression as follows:

$$
\mathrm{a}=\frac{k}{A_{1}+A_{2}\left(1-A_{3} k^{-0.9}\right)^{q}}
$$

Figure 10 is the curve about the permeability coefficient $\mathrm{k}$ and the coefficient $\mathrm{a}$. When the permeability coefficient is smaller than the rainfall intensity, the values of a derived by the different rainfall intensity curves are equal, that is, the infiltration amount per unit time is equal. When the permeability coefficient exceeds the rainfall intensity, the infiltration amount per unit time has relation to the rainfall intensity. In the stable stage of the curve, as the permeability coefficient increases, the coefficient a decreases slightly. This is because too high permeability coefficient will make water at the toe of the slope flow into the slope, so that the pore water pressure decreases, and the effective stress increases. However, the numerical simulation process does not consider the deduction effect when water enters the soil, so the increase of permeability coefficient leads to slower increase in the landslide probability.

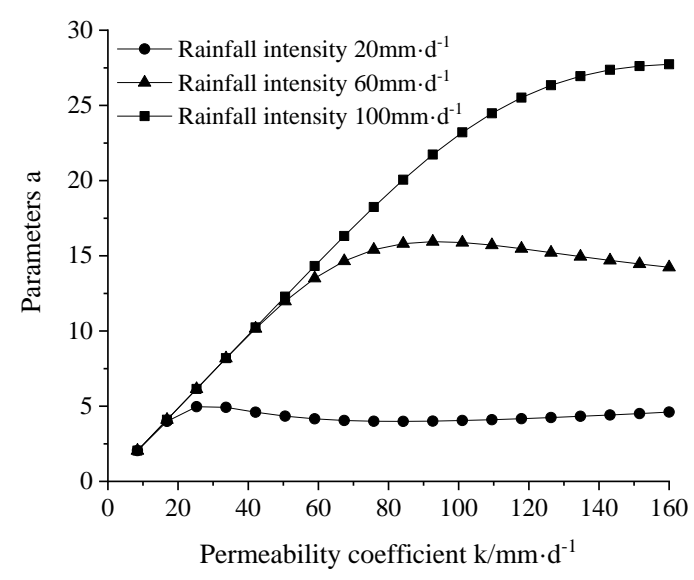

Fig 10: $k$-a fitting curve diagram

Figure 11-Figure 13 are the fitting effect diagrams of the permeability coefficient and the correlation coefficient of the $\mathrm{q}-\mathrm{b}$ curve. According to the scatter plot shape, the selected fitting formula is as follows:

$\mathrm{k}-b_{1}$ fitting formula expression:

$$
\mathrm{b} 1=\frac{\mathrm{B}_{1} \mathrm{k}}{1+\mathrm{B}_{2} \mathrm{k}}
$$

$\mathrm{k}-b_{2}$ fitting formula expression:

$$
\mathrm{b}_{2}=\mathrm{B}_{3}
$$

$\mathrm{k}-b_{3}$ fitting formula expression:

$$
\mathrm{b}_{3}=\mathrm{B}_{4} \mathrm{k}^{-\mathrm{B}_{5}+\mathrm{B}_{6}}
$$

The coefficient $\mathrm{B}_{1}$ obtained by fitting the $30^{\circ}$ slope angle model is $9.3, \mathrm{~B}_{2}$ is $0.005, \mathrm{~B}_{3}$ is $1.85, \mathrm{~B}_{4}$ is $20.8, \mathrm{~B}_{5}$ is $0.936, B_{6}$ is 0.11 . The goodness of fit of the model under each working condition is shown in Table 5 .

According to formulas (8) (14) (15) (16), the functional relationship between the coefficient b and the permeability coefficient $\mathrm{k}$ can be obtained, with expression as follows:

$$
t_{0}=\frac{B_{1} k q^{-B_{3}}}{1+k B_{2}}+B_{4} k^{B_{5}}+B_{6}
$$

ISSN: 0010-8189

(C) CONVERTER 2020 
Figure 14 shows the $\mathrm{k}-t_{0}$ curve when the slope angle is $30^{\circ}$. It can be seen that as the permeability coefficient increases, the time $t_{0}$ required to reach the initial point of the landslide probability gets shorter, which displays the same law as the coefficient a. Under high permeability coefficient, the moisture at the slope angle is discharged to the inside or outside of the slope, which is more obvious under light rain.

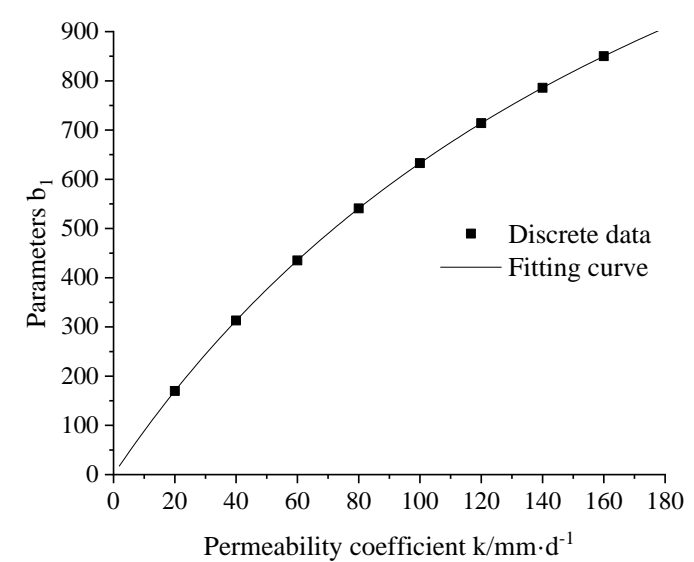

Fig 11: $k-b_{1}$ curve fitting

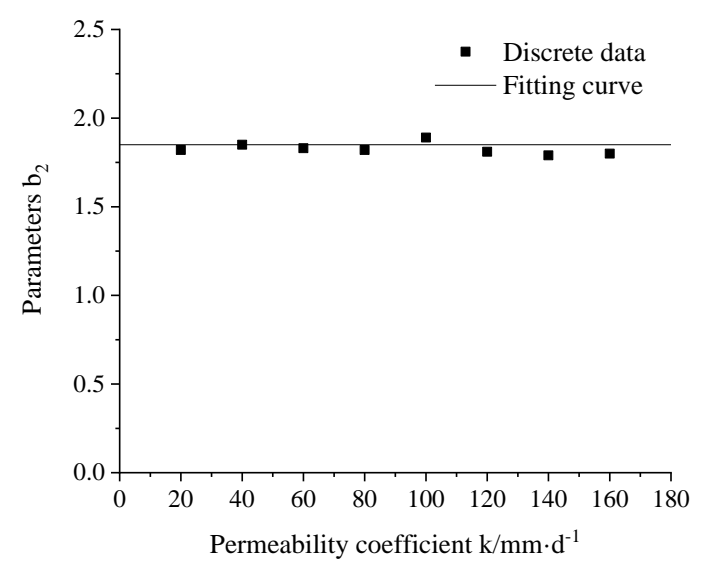

Fig 12: $k-b_{2}$ curve fitting

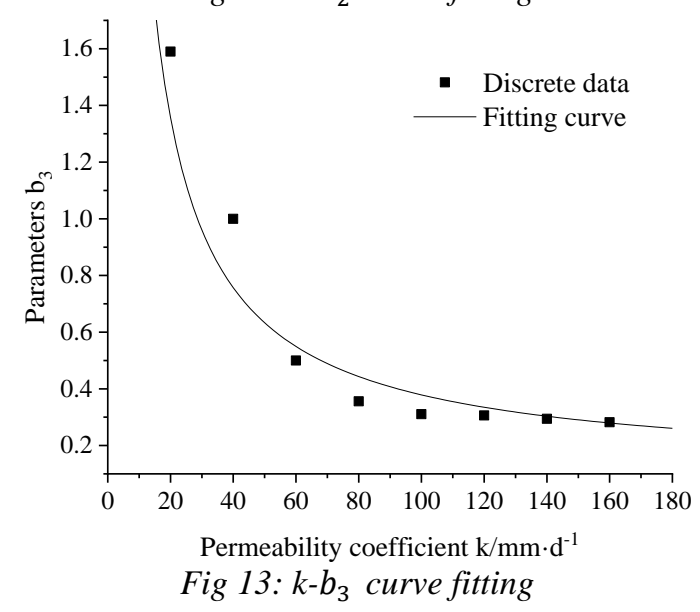

ISSN: 0010-8189 


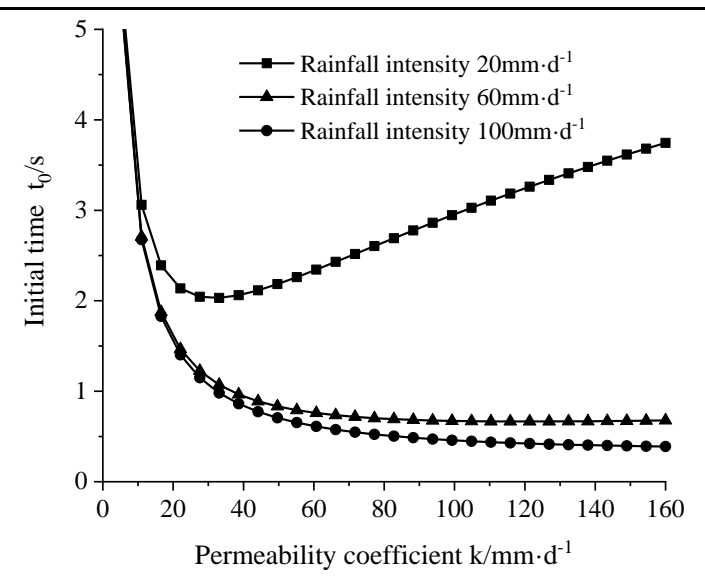

Fig 14: $k$ - $t_{0}$ curve change law

According to formulas (7), (13) and (17), the functional relationship between the slope state value $\mathrm{Z}$ and the rainfall time $\mathrm{t}$, rainfall intensity $\mathrm{q}$ and permeability coefficient $\mathrm{k}$ can be obtained, with expression as follows:

$$
\mathrm{Z}=\frac{k\left(\mathrm{t}-\frac{B_{1} k q^{-}-B_{3}}{1+k B_{2}}-B_{4} k^{B_{5}}-B_{6}\right)}{A_{1}+A_{2}\left(1-A_{3} k^{-0.9}\right)^{q}}-5
$$

Table 5 Goodness of fit of landslide probability formula considering permeability coefficient $\mathrm{k}$

\begin{tabular}{|c|c|c|c|}
\hline Independent variable & Dependent variable & Fitting formula & $\begin{array}{c}\text { Determination coefficient } \\
R^{2} \text { (average value) }\end{array}$ \\
\hline \multirow{4}{*}{$\begin{array}{c}\text { penetration } \\
\text { coefficient } \mathrm{k} / \mathrm{mm} \cdot \mathrm{d}^{-1}\end{array}$} & $\mathrm{a}_{1}$ & $\mathrm{a}_{1}=\frac{\mathrm{A}_{1}}{\mathrm{k}}$ & 0.95 \\
\cline { 2 - 4 } & $\mathrm{a}_{2}$ & $\mathrm{a}_{2}=\frac{\mathrm{A}_{2}}{\mathrm{k}}$ & 0.96 \\
\cline { 2 - 4 } & $\mathrm{a}_{3}$ & $\mathrm{a}_{3}=1-\mathrm{A}_{3} \mathrm{k}^{-0.9}$ & 0.93 \\
\cline { 2 - 4 } & $\mathrm{b}_{1}$ & $\mathrm{~b}_{1}=\frac{\mathrm{B}_{1} \mathrm{k}}{1+\mathrm{B}_{2} \mathrm{k}}$ & 0.97 \\
\cline { 2 - 4 } & $\mathrm{b}_{2}$ & $\mathrm{~b}_{2}=\mathrm{B}_{3}$ & 0.94 \\
\cline { 2 - 4 } & $\mathrm{b}_{3}$ & $\mathrm{~b}_{3}=\mathrm{B}_{4} \mathrm{k}^{-\mathrm{B}_{5}}$ & 0.91 \\
\hline
\end{tabular}

4.4 Consider the impact of slope angle

To increase the slope angle's impact on the slope state value, take the slope angle tangent $i$ as the independent variable, and the coefficients $A_{i}$ and $B_{i}$ as the dependent variables. The fitting formula is in the form of a polynomial. See Table 6 for the fitting result and goodness of fit

\section{Checking Calculation of the Probability Model of Heavy Rain-induced Muck Soil Landslide}

The logistic regression analysis equation of nonlinear classification has been obtained above. After randomly selecting the slope model, the landslide probability model is used to predict the slope landslide probability, with checking calculation results shown in Table 7. The error range between the predicted value and the calculated value

ISSN: 0010-8189

(C) CONVERTER 2020 
of the numerical model is within $10 \%$, suggesting reasonable and reliable forecast results.

On this basis, the risk assessment grades of heavy rain-induced landslides are divided, as shown in Table 8 [18].

Table 6 Fitting results and goodness of the landslide probability formula considering the slope angle tangent $\mathrm{i}$

\begin{tabular}{|c|c|c|c|}
\hline \multirow{5}{*}{ Independent variable } & $\begin{array}{c}\text { Dependent } \\
\text { variable }\end{array}$ & Fitting formula & $\begin{array}{c}\text { Determinatio } \\
\mathrm{n} \\
\text { coefficient } \\
R^{2}\end{array}$ \\
\hline \multirow{5}{*}{ Slope angle tangent } & $A_{1}$ & $\mathrm{~A}_{1}=-49.3 \mathrm{i}^{5}+301.1 \mathrm{i}^{4}-715.8 \mathrm{i}^{3}+834.3 \mathrm{i}^{2}-480.2 \mathrm{i}+110.7$ & 0.98 \\
\cline { 2 - 5 } & $A_{2}$ & $A_{2}=100 i^{2}-229.4 i+162.6$ & 0.99 \\
\cline { 2 - 5 } & $A_{3}$ & $A_{3}$ & 0.98 \\
\cline { 2 - 5 } & $B_{1}$ & $B_{2}=-1511 \mathrm{i}^{6}-9933 \mathrm{i}^{5}+26480 \mathrm{i}^{4}-36600 \mathrm{i}^{3}+27610 \mathrm{i}^{2}-10760 \mathrm{i}+1697$ & 0.99 \\
\cline { 2 - 5 } & $B_{3}$ & $B_{3}=-26.6 \mathrm{i}^{5}+149.1 \mathrm{i}^{4}-329.5 \mathrm{i}^{3}+358.2 \mathrm{i}^{2}-191.7 \mathrm{i}+41.6$ & 0.99 \\
\hline & $B_{4}$ & $=5581 \mathrm{i}^{6}-37690 \mathrm{i}^{5}+103900 \mathrm{i}^{4}-149500 \mathrm{i}^{3}+118600 \mathrm{i}^{2}-49220 \mathrm{i}+83$ & 0.97 \\
\cline { 2 - 5 } & $B_{5}$ & $B_{5}=0.1 i^{3}+1.8 i^{2}-4.2 i+2.8$ & 0.98 \\
\hline
\end{tabular}

Table 7 Verification and analysis of project cases

\begin{tabular}{|c|c|c|c|c|c|c|c|}
\hline $\begin{array}{c}\text { Slope } \\
\text { number }\end{array}$ & $\begin{array}{c}\text { Rainfall } \\
\text { time t/d }\end{array}$ & $\begin{array}{c}\text { Rainfall } \\
\text { intensity } \\
\mathrm{q} / \mathrm{mm} \cdot \mathrm{d}^{-1}\end{array}$ & $\begin{array}{c}\text { Permeability } \\
\text { coefficient } \\
\mathrm{k} / \mathrm{mm} \cdot \mathrm{d}^{-1}\end{array}$ & $\begin{array}{c}\text { Slope } \\
\text { angle } \\
\text { tangent i }\end{array}$ & $\begin{array}{c}\text { Landslide } \\
\text { probability } \\
\text { prediction /\% }\end{array}$ & $\begin{array}{c}\text { Monte Carlo } \\
\text { landslide } \\
\text { probability/\% }\end{array}$ & $\begin{array}{c}\text { safety } \\
\text { coefficient }\end{array}$ \\
\hline 1 & 3.5 & 20 & 100 & 0.58 & 12 & 10 & 1.06 \\
\hline 2 & 0.8 & 88 & 80 & 0.58 & 87 & 80 & 0.99 \\
\hline 3 & 1.6 & 24 & 60 & 0.84 & 85 & 83 & 0.98 \\
\hline 4 & 0.3 & 72 & 120 & 1.19 & 19 & 26 & 1.03 \\
\hline 5 & 1.5 & 22 & 20 & 1.43 & 22 & 12 & 1.05 \\
\hline 6 & 0.4 & 60 & 120 & 1.43 & 89 & 95 & 0.96 \\
\hline 7 & 0.7 & 24 & 40 & 1.73 & 53 & 50 & 1.01 \\
\hline 8 & 0.2 & 128 & 160 & 1.73 & 89 & 90 & 0.98 \\
\hline
\end{tabular}

Table 8 Risk levels of heavy rain-induced landslide

\begin{tabular}{|c|c|c|}
\hline Stability description & Destruction probability/\% & Stability level \\
\hline Stable & $<5$ & I \\
\hline Relatively stable & $5 \sim 30$ & II \\
\hline General & $30 \sim 60$ & III \\
\hline Dangerous & $60 \sim 90$ & IV \\
\hline Highly dangerous & $>90$ & V \\
\hline
\end{tabular}

\section{Discussion}

Rao Yunzhang [19] used logistic regression model and certainty coefficient CF to establish the probability prediction model of rare earth mine landslide. Zhang Zhen [20] used binomial logistic regression model to analyze the impact of daily rainfall on the occurrence probability of landslide. The above-mentioned documents all adopt standard logistic

ISSN: 0010-8189

(C) CONVERTER 2020 
regression analysis method of linear classification. When considering multiple impact factors, this method has big restrictions over the value range of the impact factor, and the accuracy is low after the range is exceeded. This paper modifies the Logistic regression analysis model, uses the logistic regression analysis method of nonlinear classification to fit the nonlinear decision boundary function by adding influencing factors successively, and then obtain the probability evaluation model suitable for muck soil landslide based on Monte Carlo method.

\section{Conclusions}

In this paper, based on the Monte Carlo method and logistic regression analysis of nonlinear classification, a method for quickly identifying landslide risk of muck soil under heavy rain is established for muck soil with slope angle of $30^{\circ} \sim 60^{\circ}$. The main conclusions are as follows:

1) This paper combines the Monte Carlo method with the logistic regression method, and replaces the linear weight function in the standard logistic regression analysis with the non-linear function $\mathrm{Z}=\mathrm{f}(\mathrm{t}, \mathrm{q}, \mathrm{k}, \tan \alpha)$. The function expression is obtained by data fitting of the numerical calculation results of the muck soil slope.

2) This method takes into account the four main influencing factors of rainfall time, rainfall intensity, permeability coefficient and slope angle. It can quickly evaluate whether there is a landslide risk in the muck soil slope under heavy rain conditions, and can avoid cumbersome numerical model calculations.

3) This method is based on the numerical calculation result data of randomly selected 5544 muck soil slope models to ensure the rationality and accuracy of the fitting formula. The error between the predicted value and the calculated value of the numerical model is within $10 \%$, indicating that the prediction result is reasonable and reliable.

\section{Acknowledgement}

This work was supported by National Key Research and Development Program of China (2018YFC0809900), National Natural Science Foundation of China (41772335), the Youth Talent Training Program and Discipline construction of high-level universities with distinctive features of North China University of Technology.

\section{References}

[1] C.Z. Liu, "Geological hazard risk identification method," Chinese Journal of Geological Hazard and Prevention, no. 29, pp. 3, 2018.

[2] M.P Zhang, J. Jia, Y. Wang, Q. Niu, Y.M. Mao, Y. Dong, "Construction of geological hazard prevention and control system based on artificial intelligence (AI)," Northwest Geology, no. 52, pp. 103-116, 2019.

[3] F. Luo, "Statistical characteristic estimation of small sample geotechnical parameters and reliability analysis of slope stability," Southwest Jiaotong University, 2017.

[4] Y. Li, "Study on prediction and early warning method of regional rainfall landslide," China University of Geosciences (Beijing), 2005.

[5] J.P. Qiao, Z.Y. Yang, H.1. Tian, "Probability analysis method for early warning of rainfall landslide," Journal of Engineering Geology, no. 17, pp. 343-348, 2009.

[6] Saha. S, Arabameri. A, Saha. A, Blaschke. T, Band. S.S, "Prediction of landslide susceptibility in rudraprayag, india using novel ensemble of conditional probability and boosted regression tree-based on cross-validation method," Science of The Total Environment, pp. 142928, 2020

[7] Hidayat. R, Sutanto. S. J, Hidayah. A, Ridwan. B, Mulyana. A, "Development of a landslide early warning system in indonesia,” Geosciences (Switzerland), no. 9, pp. 451, 2019.

[8] J. H. Lee, H. Kim, H. J. Park, J. H Heo, “Temporal prediction modeling for rainfall-induced shallow landslide hazards using extreme value distribution,” Landslides, no. 18, pp. 321-338, 2020.

ISSN: 0010-8189 
[9] Z.H. Wang, J.X. Zhang, S.W. Yang, L.l. Liu, "Study on early warning of rainfall-type loess landslide in Lanzhou based on Logistic model," Science of surveying and Mapping, no. 45, pp. 142-148+155, 2020.

[10] X.J. Wei, X.M. Zhao, C.L. Ma, X.J. Lei, "Reduction and logical regression prediction model of rainfall landslide disaster," Chinese Journal of Safety Science, no. 28, pp. 1-6, 2018.

[11] P. Wang, "Design and implementation of kernel logic regression algorithm for unbalanced data classification," Xi'an University of Electronic Science and Technology, 2015.

[12] Heddam. S, Ikram. R.M.A, Z. Liang, Zounemat-Kermani. M, B, Li, "Least square support vector machine and multivariate adaptive regression splines for streamflow prediction in mountainous basin using hydro-meteoro- logical data as inputs," Journal of Hydrology, pp. 124371, 2019.

[13] S. Duan, S. Yu, Y. Chen, Principe. J. C, "On kernel method-based connectionist models and supervised deep learning without backpropagation," Neural Computation, no. 32, pp. 1-39, 2019.

[14] Sitepu. N. B, Sawaluddin, Zarlis. M, Efendi. S, Dhany. H. W, "Analysis of decision tree and smooth support vector machine methods on data mining," Journal of Physics: Conference Series, no. 1255, pp. 012067, 2019.

[15] José ngel. M, Ricardo. G.R, María. L.L, Rodriguez-Benitez, L, "Discrete choice modeling using kernel logistic regression," Transportation Research Procedia, no. 47, pp. 457-464, 2020.

[16] D.L. Sun, "Study on landslide susceptibility regionalization and rainfall-induced landslide prediction and early warning based on machine learning," East China normal University, 2019.

[17] J. Guo, "Slope stability analysis of slag-soil accumulation," North China University of Water Conservancy and Hydropower, 2018.

[18] W.Q. Luo, R.Q. Huang, X.Y. Zhang, "Theory and application of probability analysis of slope stability," China University of Geosciences Press, 2003.

[19] Y.Z. Rao, X.Y. Zhang, X.Z. Li, Y.G. Huang, Y.S. Zhang, “Application of landslide probability in slope stability analysis," Disaster Science, no. 31, pp. 7-1016, 2016.

[20] Z. Zhang, "Field test of rainfall infiltration of loess slope in northern Shaanxi and its disaster early warning," Xi'an University of Technology, 2018. 